\title{
Bullying behaviour in schools, socioeconomic position and psychiatric morbidity: a cross- sectional study in late adolescents in Greece
}

Konstantina Magklara ${ }^{1,4^{*}}$, Petros Skapinakis ${ }^{1}$, Tatiana Gkatsa ${ }^{1}$, Stefanos Bellos ${ }^{1}$, Ricardo Araya ${ }^{2}$, Stylianos Stylianidis ${ }^{3}$ and Venetsanos Mavreas ${ }^{1}$

\begin{abstract}
Background: Bullying is quite prevalent in the school setting and has been associated with the socioeconomic position and psychiatric morbidity of the pupils. The aim of the study was to investigate the association between bullying and socioeconomic status in a sample of Greek adolescents and to examine whether this is confounded by the presence of psychiatric morbidity, including sub-threshold forms of illness.

Methods: 5,614 adolescents aged 16-18 years old and attending 25 senior high schools were screened and a stratified random sample of 2,427 were selected for a detailed interview. Psychiatric morbidity was assessed with a fully structured psychiatric interview, the revised Clinical Interview Schedule (CIS-R), while bullying was assessed with the revised Olweus bully/victim questionnaire. The following socio-economic variables were assessed: parental educational level and employment status, financial difficulties of the family and adolescents' school performance. The associations were investigated using multinomial logit models.

Results: $26.4 \%$ of the pupils were involved in bullying-related behaviours at least once monthly either as victims, perpetrators or both, while more frequent involvement (at least once weekly) was reported by $4.1 \%$. Psychiatric morbidity was associated with all types of bullying-related behaviours. No socioeconomic associations were reported for victimization. A lower school performance and unemployment of the father were significantly more likely among perpetrators, while economic inactivity of the mother was more likely in pupils who were both victims and perpetrators. These results were largely confirmed when we focused on high frequency behaviours only. In addition, being overweight increased the risk of frequent victimization.
\end{abstract}

Conclusions: The prevalence of bullying among Greek pupils is substantial. Perpetration was associated with some dimensions of adolescents' socioeconomic status, while victimization showed no socioeconomic associations. Our findings may add to the understanding of possible risk factors for bullying behaviours in adolescence.

Keywords: Bullying, Adolescents, Socioeconomic status, Psychiatric morbidity, Victims, Perpetrators

\section{Background}

Bullying is quite prevalent in the school setting and has important adverse effects on many areas of the adolescents' life. It is a specific type of aggression in which an intension to harm or disturb can be identified, occurs repeatedly over time and there is an imbalance of power, with a more powerful person or group attacking

\footnotetext{
* Correspondence: nadia.magklara@gmail.com

'Department of Psychiatry, University of loannina, School of Medicine, loannina, Greece

Full list of author information is available at the end of the article
}

a less powerful one [1]. According to a widely used research definition of bullying a student is being bullied or victimized when he or she is exposed, repeatedly and over time, to negative actions on the part of one or more other students [2]. Negative actions are further defined as when someone (the "perpetrator") intentionally inflicts, or attempts to inflict, injury or discomfort upon another (the "victim"). Negative actions can be verbal, including threatening, taunting, teasing, or namecalling, or physical, such as hitting, kicking, pushing, shoving or pinching. Being a victim of bullying has been 
associated with lower self-esteem [3], depressive symptomatology [4-7], anxiety [3], physical and psychosomatic symptoms [8-10], suicidal ideation [11,12] and suicide [13]. On the other hand, being a perpetrator has been associated with aggression [14], antisocial personality, criminality and substance abuse [15]. As regards the direction of causality, studies have shown that bullying appears to be a potential risk factor for mental health problems, since it usually precedes the onset of emotional difficulties [5].

A large number of studies conducted in different countries indicate that bullying at school occurs all over the world and is not confined to any geographical region, socioeconomic or cultural group. The prevalence, however, of bullying varies considerably between countries. Studies show prevalence rates of the overall phenomenon between $8 \%$ in Germany [16] and 29.9\% in the United States [17], 30\% in Italy [18] and 40\% in Korea [19]. Prevalence rates of perpetrators vary between $4 \%$ and $50 \%$ [20], while rates of victims of bullying vary between $4.1 \%$ for girls in Sweden and 36.3\% for boys in Lithuania [21]. A recent international study which investigated the prevalence of bullying victimization in 66 countries and territories reports that on average $32,1 \%$ of the children were bullied at school at least once within the past 2 months, while $37,4 \%$ of children were bullied at least one day within the past 30 days [22]. Boys are more often perpetrators than girls [23], while rates of victimization may not differ between the two genders $[17,24,25]$. Both behaviors appear to be more common in younger ages [17,26,27].

According to Craig et al. the prevalence of bullying combined (i.e., bullying others, being bullied and being both a bully and a victim) in Greece was $41.3 \%$ and Greece occupied the third place among 40 countries in the number of adolescent students being involved in bullying-related behaviours [23]. Possible explanations of this relative high prevalence are the lack of national policies against bullying in Greece, as well as a number of cultural variations, for example the way bullying is conceptualized and understood [28].

The cross-national variations in the prevalence of bullying may reflect the different distribution of culturespecific risk factors among countries and the different methods used in research. Regarding socioeconomic status, lower parental education [26] and poorer academic achievement of the student in school have been associated with bullying [17]. Recently, an international study showed that being a victim was more common among adolescents from families of lower socioeconomic position and this association appeared to be relatively strong across several countries [29]. Another study, which investigated socioeconomic associations of bullying using a sample of preschool children, has also shown that children from families with lower educational level present an increased risk of victimization [30] A study conducted in Germany and England has also reported associations between social class and both victims and perpetrators [16]. Moreover, not only the presence but also the persistence of bullying over time has been associated with lower socioeconomic status of the family [31]. A recent review suggests that bullying is not only a socially patterned life experience, but it tracks over time and there are indications of a socially differential vulnerability to its effects. Exposure to bullying may be an element of a pathway through which socioeconomic position in adolescence contributes to adult health inequalities [32]. At the school level, Whitney and Smith (1993) reported that junior and middle schools with higher proportions of families from lower social classes had a higher prevalence of bullying [24]. Finally, at the country level countries with higher income inequality had a higher prevalence of bullying among preadolescents than countries with lower income inequality [33].

As described in the previous paragraphs psychiatric morbidity has been associated with bullying-related behaviours. In addition previous studies have shown a strong association between several socioeconomic variables and psychiatric morbidity [34-36]. Therefore, an important confounding variable in the association between socioeconomic status and bullying is the presence of psychiatric morbidity. Not all previous studies have adjusted for the full spectrum of psychiatric morbidity including subthreshold forms of illness. It is likely that a more detailed assessment of psychiatric morbidity including also subthreshold forms of illness could explain part of the confounding and could reduce possible associations between bullying and socioeconomic status. It is noted that confounding is an important issue irrespective of the study design and could influence the results of both cross-sectional and longitudinal studies. Clarifying whether low socioeconomic status is associated with bullying after adjustment for all potential confounding factors may contribute to the discussion about possible causal pathways of bullying-related behaviours.

The aim of the present study was to investigate the association between bullying-related behaviours (being either a victim or a perpetrator or both) and socioeconomic status in a sample of adolescents attending senior high schools in Greece. Since the burden of psychiatric morbidity is significant in adolescence [37], we explored possible effects of the full spectrum of psychiatric morbidity on the association between bullying and socioeconomic indicators. We made the hypothesis that socioeconomic indicators would be independently associated with bullying-related behaviours after adjusting for psychiatric morbidity. We have also investigated the 
association of obesity problems with bullying-related behaviours, since there is evidence that obesity or overweight may be associated with both bullying and socioeconomic status [38-40].

\section{Methods}

\section{Description of the data set}

The data reported here are derived from the "Epirus School Project" [35] which is a cross-sectional survey carried out in selected upper secondary schools in Greece. The study was approved by the Ethical committee of the Ministry of Education and the Greek Pedagogical Institute (decision number: 61390/g2/19-06-2006) and was conducted according to the Helsinki declaration. The study was also approved by the Head of each participating School. The principal aim of the survey was to investigate the prevalence and associations of common mental disorders in late adolescence.

\section{Secondary education in Greece}

Secondary education in Greece is distinguished into lower secondary (grades 7-9; ages 13-15 years; attendance is compulsory) and upper secondary (grades 1012 ; ages 16-18 years; attendance is not compulsory). Upper secondary schools are further distinguished into senior high schools (Lyceum) and technical vocational schools with the majority of students (75\%) attending senior high schools. In the "Epirus School Project" only senior high schools were selected (age of pupils 16-18 years). At the time of the design of the study approximately 75,000 students attended 1,193 senior high schools.

\section{Sampling of schools and pupils}

Schools were selected according to the following rules: a) all senior high schools of the major cities in the north-western part of Greece (regions of Epirus and Aetoloakarnania) due to the proximity of this area to the University of Ioannina, b) all senior high schools in one randomly selected district of the Athens Metropolitan Area (the district of Kallithea was selected), c) all senior high schools of the island of Paros in the Aegean Sea (the island was conveniently selected). A total of 25 schools took part in the study. The median number of participants per school was 225 pupils ranging from 138 to 425. The main fieldwork took place between January 2007 and April 2008. All students in the selected schools were invited to participate in the study, while the participation was voluntary. Consent was actively obtained from both the participants and their parents.

\section{Design of the study and data collection procedure}

The study used a two-phase design [41]. In the first phase, all consenting students $(\mathrm{N}=5,614$, response rate
$82 \%)$ were administered a brief screening instrument in the classroom. The screening instrument of the first phase was developed from the revised clinical interview schedule (CIS-R) used in the second phase of the study. Students were selected for the second phase psychiatric interview using a stratified random sampling procedure according to the scores on the screening questionnaire: $100 \%$ of those scoring high on the screening instrument ( $>75$ th percentile), $30 \%$ of those scoring in the middle and $10 \%$ of those scoring low $(<25$ th percentile). The second phase $(\mathrm{N}=2,431$, response rate $95 \%)$ consisted of the computerized version of a fully-structured psychiatric interview (see next section) and was carried out in the computer laboratories of the schools. It is noted that in two schools (both in the island of Paros) all consenting students were interviewed (that is the two phases were merged into one). The reason was the availability of the fieldworkers of the island of Paros, which allowed us to provide the instrument of the CIS-R interview in full to all consenting students. From the remaining 1,960 pupils who were selected according to the stratified random sampling procedure, 926 (47.2\%) were on the $100 \%$ stratum, $866(44.2 \%)$ on the $30 \%$ stratum and $168(8.6 \%)$ on the $10 \%$ stratum. Four out of the 2,431 selected pupils had missing values on the sociodemographic questions (administered in the first phase of the study) and therefore 2,427 pupils were used in the final analysis.

\section{Assessment of psychiatric morbidity: the revised clinical interview schedule (CIS-R)}

Psychiatric symptoms were assessed with the revised clinical interview schedule (CIS-R), a fully structured psychiatric interview designed to be used by trained lay interviewers [42]. The CIS-R was the main instrument used in the national psychiatric morbidity surveys in the UK [43] and has been used in several other similar surveys around the world. A computerized version has also been developed and found to be comparable with the regular interview [44]. The CIS-R was originally designed to assess symptoms in participants above 16 years old but has been previously used in teenagers above 14 years old in Australia [45]. The CIS-R assesses the presence and severity of common psychological symptoms (somatic symptoms, fatigue, concentration/ memory problems, sleep problems, irritability, depressive mood, depressive ideas, general worry, worry about physical health, free-floating anxiety, phobias, panic anxiety, compulsions and obsessions). Two screening questions in each section ask about the presence of the symptom during the past month and then there is a more detailed assessment of the presence, frequency, duration and severity of the symptom during the past seven days. Based on the above-mentioned characteristics of the 
symptoms each one of the 14 symptoms is rated with an individual score on a scale ranging from 0 to 4 (except depressive ideas scored from 0 to 5 ).

In the first phase of the study we used the screening questions of the several symptom sections of the CIS-R. To simplify the screening we excluded the somatic symptoms section, the depressive ideas section (since it is branched through the depression section), and the panic section (it is branched through the anxiety section). We used the main screening question for the symptoms of fatigue, concentration problems, memory problems, worry about physical health, free-floating anxiety, phobias, obsessions, and compulsions (eight questions) and the two screening questions for the symptoms of sleep problems (one question for difficulty sleeping and one for sleeping more than usual), irritability, depression (depressed mood and loss of interest) and anxiety (eight questions). Therefore the screening instrument consisted of 16 yes-no questions. The full interview was taken by those students selected for the second phase of the study.

The Greek version of the CIS-R was translated and back-translated using the procedure recommended by the World Health Organization http://www.who.int/substance_abuse/research_tools/translation/en/index.html. The psychometric properties of the Greek version of the CIS- $\mathrm{R}$ including its factor structure and internal consistency have been reported by Skapinakis et al. 2010 [46]. An internal consistency reliability analysis showed that item-test correlations ranged from 0.42 to 0.74 , itemrest correlations ranged from 0.30 to 0.67 and Cronbach's alpha ranged from 0.84 to 0.87 with an overall alpha for CIS-R of 0.86. A test-retest reliability of the CIS-R was carried out in a subset of the present data set (two schools of the city of Ioannina with an interval between assessments of 2 weeks) and was found to be 0.84 [35].

For the purposes of the present study psychiatric morbidity can be assessed either in a dimensional way, using the total score on the CIS-R (by adding-up all 14 symptom dimensions), or in a categorical form using diagnostic categories. We chose to use the total score in our analyses because in that way we are able to adjust for the full spectrum of psychiatric morbidity including subthreshold forms of illness. To better illustrate the association of bullying with the severity of psychiatric morbidity we defined four groups of severity: "no/minimal symptoms" (CIS-R score $=0-5$ ), "subthreshold symptoms" (CIS-R score = 6-11), "mild symptoms" (CIS-R score $=12-17$ ) and "severe symptoms" (CIS-R score $>=$ $18)$. A score of 12 or above on the CIS-R indicates caseness $[42,47]$, a score of 6-11 indicates some symptoms of mental disorder, a score of 0-5 indicates little evidence of mental disorder [47], while a score of 18 or more has been used as an indicator of severe morbidity [48].

\section{Assessment of school bulling}

Involvement in bullying either as a perpetrator (bully others) or as a victim (being bullied by others) was investigated in the second phase of the study. We used two questions, one for being bullied and one for bullying others, taken from the revised Olweus Bully/Victim Questionnaire [49] which was also used in a WHO youth health study [50]. An introductory sentence defined bullying as follows:

"The next questions are about bullying. We say a pupil is being bullied when another pupil, or a group of pupils, says or does nasty and unpleasant things to him or her. It is also bullying when a pupil is teased repeatedly in a way he or she doesn't like. But it is not bullying when two pupils of about the same strength quarrel or fight."

The respondents were further asked how frequently they had been bullied or had bullied others during the last 2 months in school. The possible answers were: "many times a week", "about once a week", "2 or 3 times a month", "about once a month" and "not at all". Based on these responses we classified participants into the following groups: a) Not involved in bullying related behaviours, either as victims or perpetrators; b) being a victim but not a perpetrator; c) being a perpetrator but not a victim; d) being both a victim and perpetrator. Regarding the cut-off for frequency, we defined two variables, one including all instances of bullying-related behaviours (i.e. at least once a month) and the other focusing on high frequency only (i.e. at least once a week).

\section{Socioeconomic variables}

We have used the following socioeconomic variables:

\section{a) Parental Education}

We assessed the educational status of both parents separately, since evidence shows that maternal socioeconomic characteristics have an equally, or even more, significant impact on child and adolescent health [51]. Pupils were asked to report their parents' highest educational level attained.

\section{b) Parental Employment}

Regarding employment, we chose to use the variable "employment type", which discriminates/distinguishes not only between employment status (employed-unemployed), but also between the different sectors of employment (self-employed, private or public sector employees). More specifically "employment type" was divided into six groups: "public sector employee"; 
"private sector employee"; "self-employed"; "pensioner"; "unemployed"; and "housewife" (as regards the mother's employment type) or "inability to work" (as regards the father's employment type). A residual category was also allowed ("else"). In Greece the legislative framework relating to the combination of family life and career (i.e. maternity leave, leave for breast-feeding/child bearing/ illness, child/family allowances etc.) differs significantly between public and private sector [52]. Greek social research employs this kind of typology which links to the institutions and the way public life is organized in Greece. As a result the distinction between selfemployed, private and public sector employees appears as very important for the country, since it determines in a great extent the way families live and function. Moreover, it is expected that the information lost by failing to ask the exact occupation, could be substituted by the information carried by the variable of education [53].

\section{c) Financial status}

We asked the adolescents to express their subjective view on any financial difficulties their family might experience recently. The specific question asked was: "How do you think that your family is doing financially?" The possible answers included: "My family experiences no financial difficulties", "My family experiences very few financial difficulties", "My family experiences some financial difficulties" and "My family experiences a lot of financial difficulties". This type of question takes into account adolescents' subjective view of their family's economic position.

\section{d) School performance}

In Greece, where typical 16-18 years-old adolescents have not yet entered the labour market, neither have they completed their education, own educational level or occupation cannot be used as a measure of personal social position. Academic performance in school has been often used in the literature as a measure of the position of the pupils in school $[36,54,55]$. We therefore included academic performance in our socioeconomic indicators by asking the participants to rate their school performance (based on their recent marks) in a scale with four choices ("excellent"; "very good"; "good"; "fair").

\section{Sociodemographic and other variables}

In the first phase of the study information was selected from the students about several sociodemographic variables (grade the pupil is currently attending, gender, parent's age, parent's marital status, number of brothers and sisters). We also obtained adolescents' self-reports on their current body weight and height, we calculated the body mass index (BMI: $\mathrm{kg} / \mathrm{m}^{2}$ ) for each student and we included this in our analyses as a categorical variable
(BMI $<19,19-22,22-25,25-30,>=30)$ in order to be able to highlight any potential non-linear associations.

\section{Statistical analyses}

The analyses were all conducted using the statistical software package STATA 10.0 (StataCorp, College Station, Texas). To take into account the potential effect of clustering of our data (since adolescents were nested into 25 schools) we first carried out a two-level logistic model (level 1: individuals, level 2: schools) in Stata using the gllamm command [56]. We also performed the models with the survey commands of Stata using school as the stratum. Results were very similar with both models and therefore in the paper we present the results using the survey commands because their use is more widespread in the literature. It should be noted that the effect of schools was negligible with an intraclass correlation coefficient close to zero $(<0.08)$. In all analyses we have used probability weights to take into account the stratified random sampling procedure.

The associations between involvement in bullyingrelated behaviours and psychiatric morbidity, socioeconomic and other variables were investigated using multinomial logistic regression models in Stata ("mlogit" command using the "svy" prefix" to obtain robust standard errors). The dependent variable was involvement in bullying (all frequencies, i.e. at least once per month) and the reference group was "not involved in bullyingrelated behaviours". We also present the analysis of the high frequency involvement only (i.e. at least once weekly) for comparison reasons and to check the sensitivity of our results in the change of the frequency cutoff. However, in the latter analysis, due to the small number of pupils with bullying-related behaviours in the fourth group of victims-perpetrators, odds ratios could not be calculated, therefore we only present odds ratios for victims vs. not involved and perpetrators vs. not involved.

Finally, since we have used categorical variables in our study, we have additionally calculated adjusted Wald tests in order to test the overall significance of our variables in the regression models, using the post-estimation command "test" in Stata.

\section{Results}

\section{Description of the sample}

Overall 5,614 students took part in the first phase of the study (55\% girls, $41 \%$ 10th grade, $31 \%$ 11th grade, $28 \%$ 12 th grade), while 2,431 students were interviewed in the second phase (59\% girls, 39\% 10th grade, 32\% 11th grade, $29 \% 12$ th grade). A detailed table of the sociodemographic characteristics of the whole sample in both phases of the study is given in Additional file 1: Table 
Table 1 Prevalence of bullying-related behaviours (at least once monthly or more) in Greek adolescents 16-18 years old attending senior high schools $(N=2,427)$

\begin{tabular}{|c|c|c|c|}
\hline & & $\mathrm{N}, \%(95 \% \mathrm{Cl})$ & \\
\hline & Male & Female & Total \\
\hline Not Involved & $N=622,65.7 \%(61.6-69.6)$ & $N=1,129, \mathbf{8 1 . 8 \%}(\mathbf{7 9 . 3}-\mathbf{8 4 . 1})$ & $N=1,751,73.6 \%(71.2-76.0)$ \\
\hline Victims only & $\mathrm{N}=72,6.7 \%(4.9-9.2)$ & $N=145,7.4 \%(6.1-8.9)$ & $N=217,7.1 \%(5.9-8.5)$ \\
\hline Perpetrators only & $N=214, \mathbf{2 1 . 5} \%(\mathbf{1 8 . 3}-\mathbf{2 5 . 2})$ & $N=109, \mathbf{7 . 4 \%}(\mathbf{5 . 8}-\mathbf{9} .4)$ & $N=323,14.6 \%(12.7-16.7)$ \\
\hline Victims \& Perpetrators & $N=80,6.1 \%(4.5-7.9)$ & $N=56,3.4 \%(2.4-4.7)$ & $N=136,4.7 \%(3.8-5.8)$ \\
\hline
\end{tabular}

S1. Due to the stratified sampling procedure there were more female than male students in the second phase.

\section{Prevalence of bullying behaviours}

Tables 1 and 2 present the prevalence of bullyingrelated behaviours by gender. Table 1 presents the prevalence for all frequencies (at least once monthly) while Table 2 for higher frequency only (at least once weekly). Regarding all frequencies, it can be seen that $26.4 \%$ of the pupils were involved either as victims, perpetrators or both. The prevalence of being a perpetrator was approximately twice that of being a victim. Out of the 676 pupils who were involved in bulling-related behaviours, 136 were both victims and perpetrators (weighted percentage 18\%). There were significant gender differences in the prevalence of bullying mainly because boys were more likely to be perpetrators compared to girls. Regarding frequent bullying, $4.1 \%$ of the pupils were involved and the same gender difference was also noted: boys were more likely to report that they had bullied others compared to girls; in contrast, there was no gender difference in victimization.

\section{Association between bullying-related behaviours (all} frequencies) and socioeconomic status variables

Odds ratios and 95\% confidence intervals for the associations of bullying-related behaviours with the sociodemographic and socioeconomic variables are shown in Tables 3 and 4 for all frequencies (at least once monthly) and for the high frequency (at least once weekly) respectively. We present odds ratios for victims, perpetrators and victims-perpetrators for all frequencies.
For the high frequency category we only present odds ratios for victims and perpetrators only due to the very small number of victims-perpetrators in this frequency.

\section{Associations with victims}

Victimization was significantly associated with psychiatric morbidity and male gender. From the socioeconomic indicators studied none was significantly associated in the adjusted model.

\section{Associations with perpetrators}

Being a perpetrator was significantly associated with psychiatric morbidity and male gender. From the socioeconomic indicators studied a lower school performance (Adjusted Wald test: $\mathrm{F}_{3,2400}=2.57, p=0.05$; odds ratio for linear term: $1.31, p=0.008)$ and father's employment status (Adjusted Wald test: $\mathrm{F}_{4,2400}=5.92, p=$ 0.0001 ) were associated with being a perpetrator. For employment this was mainly due to the unemployment of the father that was associated with an increased risk of being a perpetrator and retirement of the father that was associated with a lower risk.

\section{Associations with victims-perpetrators (both behaviours occurring at the same time)}

Male gender and psychiatric morbidity were significantly associated with an increased risk of showing both behaviours at the same time (victims and perpetrators). In addition, being a younger pupil (attending 10th grade) was also associated with an increased risk (Adjusted Wald test: $\mathrm{F}_{2,2400}=5.47, p=0.004$ )

Regarding the socioeconomic indicators, mother's employment status was associated with being a victimperpetrator (Adjusted Wald test: $\mathrm{F}_{4,2400}=2.54, p=$ 0.04 ). This was mainly due to a higher risk for those

Table 2 Prevalence of bullying-related behaviours (at least once weekly or more) in Greek adolescents 16-18 years old attending senior high schools $(\mathrm{N}=\mathbf{2 , 4 2 7})$

\begin{tabular}{|c|c|c|c|}
\hline & Male & Female & Total \\
\hline Not Involved & $N=917,93.9 \%(\mathbf{9 1 . 7 - 9 5 . 5 )}$ & $N=1,400,98.0 \%(97.2-98.6)$ & $N=2,317, \mathbf{9 5} .9 \%(\mathbf{9} 4.8-96.8)$ \\
\hline Victims only & $N=18, \mathbf{1} .3 \%(\mathbf{0} .7-2.5)$ & $N=28,1.3 \%(0.8-2.0)$ & $N=46,1.3 \%(0.9-1.9)$ \\
\hline Perpetrators only & $N=50,4.6 \%(3.2-6.6)$ & $N=14, \mathbf{0 . 7} \%(\mathbf{0 . 4}-\mathbf{1 . 3})$ & $N=64,2.7 \%(1.9-3.7)$ \\
\hline Victims \& Perpetrators & $N=4,0.2 \%(0-0.6)$ & $N=0,0 \%(N A)$ & $N=4, \mathbf{0 . 1} \%(0-0.3)$ \\
\hline
\end{tabular}

${ }^{1}$ Actual number of observations; percentages in comparison are weighted to take into account the stratified random sampling procedure. Chi ${ }_{(3)}{ }^{2}=37.52, \mathrm{p}<$ 0.001 
Table 3 Associations of bullying-related behaviours (at least once monthly) with socioeconomic variables and psychiatric morbidity.

\begin{tabular}{|c|c|c|c|}
\hline & \multicolumn{3}{|c|}{$\begin{array}{c}\text { (base }=\text { Not involved in bullying-related behaviours) } \\
\text { OR }(95 \% \mathrm{Cl})\end{array}$} \\
\hline & Victims & Perpetrators & Victims-Perpetrators \\
\hline Female Gender & $0.56(0.37-0.85)$ & $0.22(0.15-0.33)$ & $0.33(0.20-0.55)$ \\
\hline \multicolumn{4}{|l|}{ Grade } \\
\hline 10th & 1.00 & 1.00 & 1.00 \\
\hline 11th & $0.80(0.49-1.29)$ & $1.39(0.95-2.04)$ & $1.37(0.77-2.43)$ \\
\hline 12th & $0.63(0.39-1.00)$ & $1.09(0.71-1.70)$ & $0.49(0.26-0.90)$ \\
\hline \multicolumn{4}{|l|}{ Father's Educational Level } \\
\hline Primary & 1.00 & 1.00 & 1.00 \\
\hline Secondary Basic & $1.04(0.52-2.06)$ & $1.00(0.52-1.93)$ & $1.30(0.57-2.96)$ \\
\hline Secondary Complete & $0.75(0.43-1.32)$ & $1.04(0.56-1.93)$ & $0.84(0.40-1.79)$ \\
\hline Technological degree & $0.65(0.30-1.42)$ & $0.98(0.48-2.01)$ & $0.34(0.13-0.93)$ \\
\hline University degree & $0.95(0.50-1.81)$ & $1.22(0.59-2.50)$ & $0.98(0.45-2.15)$ \\
\hline \multicolumn{4}{|l|}{ Mother's Educational Level } \\
\hline Primary & 1.00 & 1.00 & 1.00 \\
\hline Secondary Basic & $0.94(0.48-1.83)$ & $1.34(0.67-2.67)$ & $1.95(0.81-4.67)$ \\
\hline Secondary Complete & $0.73(0.42-1.27)$ & $1.14(0.63-2.07)$ & $1.10(0.51-2.37)$ \\
\hline Technological degree & $0.48(0.22-1.02)$ & $0.52(0.24-1.15)$ & $1.66(0.65-4.24)$ \\
\hline University degree & $0.70(0.29-1.67)$ & $0.94(0.45-1.96)$ & $1.58(0.62-4.05)$ \\
\hline \multicolumn{4}{|l|}{ Financial Difficulties } \\
\hline No & 1.00 & 1.00 & 1.00 \\
\hline Very few & $1.38(0.85-2.23)$ & $1.18(0.79-1.76)$ & $1.14(0.67-1.95)$ \\
\hline Some/A lot & $1.22(0.71-2.11)$ & $1.33(0.77-2.30)$ & $1.41(0.72-2.76)$ \\
\hline \multicolumn{4}{|l|}{ School Performance } \\
\hline Excellent & $2.05(0.90-4.66)$ & $0.53(0.26-1.11)$ & $1.35(0.61-3.01)$ \\
\hline Very good & $1.41(0.83-2.39)$ & $0.53(0.33-0.86)$ & $0.86(0.43-1.71)$ \\
\hline Good & $1.41(0.85-2.36)$ & $0.79(0.52-1.21)$ & $1.23(0.68-2.21)$ \\
\hline Fair & 1.00 & 1.00 & 1.00 \\
\hline \multicolumn{4}{|l|}{ Father's Employment Type } \\
\hline Public sector employee & 1.00 & 1.00 & 1.00 \\
\hline Private sector employee & $1.02(0.58-1.78)$ & $0.87(0.51-1.49)$ & $0.70(0.38-1.27)$ \\
\hline Self-employed & $1.21(0.76-1.91)$ & $1.61(0.99-2.63)$ & $0.92(0.51-1.68)$ \\
\hline Retired & $0.77(0.31-1.92)$ & $0.32(0.14-0.71)$ & $0.89(0.22-3.60)$ \\
\hline Unemployed/Other & $2.28(0.86-6.05)$ & $2.32(1.19-4.51)$ & $0.73(0.24-2.26)$ \\
\hline \multicolumn{4}{|l|}{ Mother's Employment Type } \\
\hline Employee (public or private) & 1.00 & 1.00 & 1.00 \\
\hline Self-employed & $1.41(0.72-2.76)$ & $1.08(0.63-1.88)$ & $2.01(0.84-4.78)$ \\
\hline Unemployed & $0.63(0.29-1.39)$ & $0.87(0.41-1.88)$ & $1.39(0.47-4.10)$ \\
\hline Looks after house & $0.67(0.40-1.11)$ & $1.00(0.65-1.57)$ & $2.11(1.20-3.69)$ \\
\hline Retired//Other & $0.47(0.21-1.06)$ & $0.86(0.39-1.91)$ & $2.53(1.16-5.52)$ \\
\hline \multicolumn{4}{|l|}{$\overline{B M I}$} \\
\hline$<19$ & 1.00 & 1.00 & 1.00 \\
\hline $19-22$ & $0.80(0.48-1.33)$ & $1.41(0.84-2.37)$ & $0.89(0.47-1.69)$ \\
\hline $22-25$ & $0.85(0.47-1.55)$ & $1.32(0.73-2.41)$ & $1.05(0.51-2.13)$ \\
\hline $25-30$ & $1.28(0.59-2.79)$ & $1.10(0.57-2.13)$ & $2.00(0.94-4.22)$ \\
\hline$>=30$ & $2.42(0.49-11.98)$ & $1.85(0.57-5.99)$ & $1.41(0.33-6.01)$ \\
\hline \multicolumn{4}{|l|}{ Psychiatric Symptoms } \\
\hline No symptoms & 1.00 & 1.00 & 1.00 \\
\hline Subthreshold symptoms & $2.15(1.03-4.50)$ & $1.65(1.04-2.60)$ & $4.52(1.94-10.54)$ \\
\hline
\end{tabular}


Table 3 Associations of bullying-related behaviours (at least once monthly) with socioeconomic variables and psychiatric morbidity. (Continued)

\begin{tabular}{lccc}
\hline Mild symptoms & $3.06(1.43-6.52)$ & $1.92(1.22-3.03)$ & $3.77(1.67-8.52)$ \\
Severe symptoms & $6.32(3.30-12.09)$ & $1.75(1.08-2.86)$ & $7.57(3.33-17.23)$ \\
\hline
\end{tabular}

Adjusted odds ratios of bullying-related behaviours in adolescents $16-18$ years old attending senior high schools in $\mathrm{Greece}(\mathrm{N}=2,427)$

OR: Odds ratio

$\mathrm{Cl}$ : Confidence Interval

pupils whose mothers were looking after the house or were retired. There was a non-significant trend for father's educational level to be associated with victimsperpetrators (Adjusted Wald test: $\mathrm{F}_{4,2400}=2.10, p=$ 0.07), mainly due to a lower risk of being a victim-perpetrator in the category "technological degree" of father's educational level.

\section{Associations with socioeconomic status variables in high frequency only}

As mentioned in methods we also present results for involvement in bullying in a higher frequency (i.e. at least once weekly) to check the sensitivity of our results in the change of the frequency cut-off.

Regarding victims the following variables were found to be associated with an increased risk: being a younger pupil (Adjusted Wald test: $\mathrm{F}_{2,2400}=3.42, p=0.03$ ), having higher psychiatric morbidity (Adjusted Wald test: $\mathrm{F}_{3,2400}=3.45, p=0.02$ ) and having a higher BMI (Adjusted Wald test: $\mathrm{F}_{4,2400}=3.20, p=0.01$ ), mainly due to an increased risk of the overweight pupils (BMI $>=30$ ). None of the socioeconomic indicators were found to be associated with an increased risk.

Regarding perpetrators, male gender, younger pupils and a higher psychiatric morbidity were also associated with an increased risk. BMI was associated in a non-linear way with a lower risk in the two extremes (Adjusted Wald test: $\left.\mathrm{F}_{4,2400}=3.18, p=0.01\right)$. From the socioeconomic indicators studied a lower school performance (Adjusted Waldt test: $\mathrm{F}_{3,2400}=3.30, p=0.02$ ) and father's employment (Adjusted Wald test: $\mathrm{F}_{4,2400}=5.34, p=0.0003$ ) were found to be associated with an increased risk as was the case in the "all frequencies" analysis. However, for father's employment this was mainly due to the self-employment category of father and not that of unemployed. It should be noted that a linear term for financial difficulties (i.e. using the variable as a continuous one) had an odds ratio of 1.67 (95\% CI: $1.01-2.84, p=0.047$ ) which was marginally significant. However, using the variable in a categorical form this was not significant (Adjusted Wald test $\mathrm{F}_{2,2400}=2.04, p=0.13$ )

\section{Discussion}

\section{Main findings}

In a sample of late adolescents attending senior high schools in Greece $26.4 \%$ of the pupils were involved in bullying-related behaviours either as victims, perpetrators or both. The prevalence of being a perpetrator was approximately twice that of being a victim, while approximately $18 \%$ of the pupils who were involved in bullying showed both behaviours. Frequent bullying (at least once weekly) was less common. In our study we confirmed the strong association of psychiatric morbidity with all types of bullying-related behaviours. The association with socioeconomic status however seems to be more complex. In victims we did not find any evidence for an association with the socioeconomic variables studied. In contrast there was some evidence that perpetrators (pupils who bully others) are more likely to come from families with an unemployed father. On the other hand, father's retirement was associated with a lower risk of perpetration. In addition the personal social position of the pupil in the school, as reflected in their school performance, is more likely to be lower in perpetrators. Economic inactivity of the mother (either housekeeping or retirement) was associated with an increased likelihood of being both a victim and perpetrator. These results were generally confirmed when we changed the cut-off of bullying frequency (from once monthly to once weekly), although in that case there was an association of bullying others (perpetrators) with self-employment of the father rather than unemployment. Of note, financial difficulties in the family did not seem to be associated with bullying-related behaviours, although in the case of the high frequency bullying there was a marginal result concerning financial difficulties and the likelihood of being a perpetrator.

\section{Comparison with other studies}

Our study indicates that bullying is an important problem for Greek youth. As mentioned above, there is considerable variability among countries in the prevalence of bullying, which has been partly attributed to sociodemographic and cultural differences and partly to methodological inconsistencies [16]. Our results are consistent with studies conducted in different countries, which used similar instruments and a similar recall period [17]. Differences in the prevalence of bullying could also be explained by the fact that bullying is more prevalent among younger pupils [17]. Several studies report age differences in pupils' understanding of the term and 
Table 4 Associations of bullying-related behaviours (at least once weekly or more) with socioeconomic variables and psychiatric morbidity.

\begin{tabular}{|c|c|c|}
\hline & \multicolumn{2}{|c|}{$\begin{array}{l}\text { (base }=\text { Not involved in bullying-related behaviours)* } \\
\text { OR }(95 \% \mathrm{Cl})\end{array}$} \\
\hline & Victims & Perpetrators \\
\hline Female Gender & $0.89(0.38-2.07)$ & $0.08(0.04-0.19)$ \\
\hline \multicolumn{3}{|l|}{ Grade } \\
\hline 10th & 1.00 & 1.00 \\
\hline 11 th & $0.55(0.26-1.18)$ & $1.25(0.61-2.56)$ \\
\hline 12th & $0.34(0.15-0.77)$ & $0.25(0.10-0.61)$ \\
\hline \multicolumn{3}{|l|}{ Father's Educational Level } \\
\hline Primary & 1.00 & 1.00 \\
\hline Secondary Basic & $1.87(0.68-5.10)$ & $1.63(0.51-5.19)$ \\
\hline Secondary Complete & $0.85(0.30-2.38)$ & $1.09(0.34-3.47)$ \\
\hline Technological degree & $0.21(0.04-0.92)$ & $0.67(0.19-2.31)$ \\
\hline University degree & $1.05(0.32-3.41)$ & $0.60(0.19-1.88)$ \\
\hline \multicolumn{3}{|l|}{ Mother's Educational Level } \\
\hline Primary & 1.00 & 1.00 \\
\hline Secondary Basic & $0.59(0.19-1.80)$ & $0.65(0.18-2.30)$ \\
\hline Secondary Complete & $0.75(0.30-1.84)$ & $0.24(0.07-0.77)$ \\
\hline Technological degree & $0.59(0.15-2.35)$ & $0.53(0.13-2.20)$ \\
\hline University degree & $0.74(0.17-3.14)$ & $0.50(0.11-2.25)$ \\
\hline \multicolumn{3}{|l|}{ Financial Difficulties } \\
\hline No & 1.00 & 1.00 \\
\hline Very few & $0.91(0.41-2.02)$ & $2.08(0.94-4.59)$ \\
\hline Some/A lot & $1.50(0.58-3.86)$ & $2.93(0.97-8.81)$ \\
\hline \multicolumn{3}{|l|}{ School Performance } \\
\hline Excellent & $1.79(0.49-6.52)$ & $0.86(0.28-2.65)$ \\
\hline Very good & $0.66(0.25-1.74)$ & $0.21(0.08-0.55)$ \\
\hline Good & $0.83(0.34-2.00)$ & $0.62(0.30-1.30)$ \\
\hline Fair & 1.00 & 1.00 \\
\hline \multicolumn{3}{|l|}{ Father's Employment Type } \\
\hline Public sector employee & 1.00 & 1.00 \\
\hline Private sector employee & $1.73(0.64-4.70)$ & $1.30(0.44-3.83)$ \\
\hline Self-employed & $1.16(0.47-2.85)$ & $4.62(1.91-11.19)$ \\
\hline Retired & $0.41(0.05-3.40)$ & $0.65(0.13-3.26)$ \\
\hline Unemployed/Other & $2.06(0.56-7.62)$ & $1.62(0.32-8.08)$ \\
\hline \multicolumn{3}{|l|}{ Mother's Employment Type } \\
\hline Employee (public or private) & 1.00 & 1.00 \\
\hline Self-employed & $0.50(0.12-2.07)$ & $0.69(0.22-2.17)$ \\
\hline Unemployed & $0.21(0.02-1.95)$ & $1.53(0.33-7.15)$ \\
\hline Looks after house & $1.15(0.47-2.81)$ & $0.63(0.26-1.50)$ \\
\hline Retired//Other & $0.22(0.02-2.45)$ & $0.20(0.04-1.11)$ \\
\hline \multicolumn{3}{|l|}{ BMI } \\
\hline$<19$ & 1.00 & 1.00 \\
\hline $19-22$ & $0.77(0.31-1.90)$ & $4.94(1.75-13.94)$ \\
\hline $22-25$ & $1.02(0.38-2.77)$ & $3.13(1.06-9.28)$ \\
\hline 25-30 & $0.62(0.19-2.01)$ & $5.49(1.48-20.38)$ \\
\hline$>=30$ & $8.86(1.89-41.77)$ & $0.50(0.05-5.68)$ \\
\hline \multicolumn{3}{|l|}{ Psychiatric Symptoms } \\
\hline No symptoms & 1.00 & 1.00 \\
\hline Subthreshold symptoms & $1.52(0.46-5.07)$ & $3.00(1.11-8.06)$ \\
\hline
\end{tabular}


Table 4 Associations of bullying-related behaviours (at least once weekly or more) with socioeconomic variables and psychiatric morbidity. (Continued)

\begin{tabular}{lll}
\hline Mild symptoms & $1.24(0.34-4.55)$ & 3.39 (1.21-9.50) \\
Severe symptoms & $\mathbf{4 . 6 7}(\mathbf{1 . 5 1 - 1 4 . 4 7 )}$ & $\mathbf{4 . 5 4}$ (1.52-13.56) \\
\hline
\end{tabular}

Adjusted odds ratios of bullying-related behaviours in adolescents $16-18$ years old attending senior high schools in $\mathrm{Greece}(\mathrm{N}=2,427$ )

* Please note that due to the small number of pupils with bullying-related behaviours in the fourth group of victims-perpetrators, odds ratios could not be calculated, therefore we only present odds ratios for victims vs. not involved and perpetrators vs. not involved

OR: Odds ratio

$\mathrm{Cl}$ : Confidence Interval

experience of bullying $[57,58]$ and results may not be comparable between studies using different age samples.

A strong and graded association was reported between psychiatric morbidity and both bullying behaviours. Similar associations have been presented by previous studies $[21,59]$. The cross-sectional design of our study does not allow us to draw any conclusions on the direction of this association. It could be argued that both directions of causality are possible. As a result the debate remains as to whether bullying-related behaviours precede the onset of mental health problems or whether people with emotional problems tend to get more involved in such behaviours. Longitudinal studies have shown that a history of bullying-related victimization predicts the onset of emotional problems, while previous emotional problems are not significantly associated with future victimization [5].

Our study has pointed out some interesting associations between socioeconomic indicators and the likelihood of being a perpetrator. Parental employment type and adolescent's school performance showed associations which are independent of the presence of psychiatric morbidity. Studies investigating bullying behaviours have often controlled for mental health problems using simple self-reported questionnaires $[17,26]$. In our study we used a fully structured psychiatric interview assessing a broad range of common psychological symptoms. As a result there is strong evidence that the socioeconomic associations reported here are independent of any possible psychiatric problems including sub-threshold symptoms.

Parental unemployment, especially of fathers, has been negatively associated with various aspects of adolescents' health and well-being [60], which may explain the associations found in our sample. Another possible mechanism mediating this association might be parental support, since parental unemployment reduces perceived parental support [61], which has been associated with less involvement in bullying-related behaviours [62]. As regards the association with the self-employment of the father, which has arisen in the analysis of the high frequency of the variables, it can be argued that selfemployment in Greece is characterized by long and flexible working-hours, flexible holidays and considerable temporal income-variations, which may cause significant insecurity in the family context and also reduce perceived parental support.

Poorer academic achievement in school, which could be considered as an indicator of school adjustment and adolescents' own position in the school setting, has been previously associated with an increased risk of being a perpetrator [17]. In our study, a lower school performance was associated with an increased risk of perpetration, while there was some evidence of a J-type association in the high frequency only, with both fair and excellent school performance being associated more strongly with frequent perpetration. It can be argued that adolescents, who think that their school performance belongs to the extreme ends of the range, may feel that they do not belong to the average group when compared to their peers, a perception which could be very stressful for the adolescent, leading perhaps to antisocial behaviours like bullying.

Parental education as an overall variable was not associated with bullying perpetration or victimization. However, some subgroups of the variable were associated with bullying-related behaviours. The category "technological degree" of father's educational level was associated with a lower risk of being a victim-perpetrator and being a frequent victim, while the category "secondary complete" of mother's educational level was associated with a lower risk of being a frequent perpetrator. Associations with parental education have been reported by previous studies that also used pupils' self-reports, as well as with studies that used parental reports [63].

Financial difficulties of the family have been often used in studies investigating socioeconomic health inequalities of children and adults $[34,64]$ and several studies confirm a relationship between low parental socioeconomic status and being a victim or a perpetrator $[16,24]$. In our study we did not find evidence that financial difficulties may be associated with bullyingrelated behaviours when all frequencies of bullying are included. When we focused however in high frequency (perhaps pointing to a more severe range of the spectrum) there was a trend for more financial difficulties in the family to be associated with an increased risk of being a perpetrator. However, this was dependent on 
the analysis (there was a marginally significant association only when the variable was treated as a continuous variable) and therefore we are unsure whether financial difficulties may have a negative impact on pupil's behaviour.

Regarding sociodemographic factors we confirmed that boys, overweight, obese and younger pupils are more frequently involved in bullying behaviours either as victims or as perpetrators [17,26,38,39]. An interesting finding in our study was the nonlinear relationship between the BMI and being a victim of bullying behaviours. Severe obesity (BMI > 30) was found to be associated with victimization only in the high frequency analysis.

\section{Limitations of the study}

When interpreting the above mentioned findings the cross-sectional nature of our study should be taken into account, since it does not allow us to make any causal inference about the association between bullying and the socioeconomic indicators studied. Furthermore, our sample did not include adolescents attending technical vocational schools but only those attending senior high schools (approximately 75\% of the school-attending adolescents of this age). Parental employment status was based on adolescents' self-report, which may result in some misclassification. However, this kind of misclassification is expected to be random. Moreover, the question about parental employment status did not include information about the exact occupation and as a result an official "occupational status" classification was not possible.

In order to calculate the body mass index of the students we have used adolescents' self-reports of their current body weight and height. Research has shown that adolescents' self-reports of height, weight and BMI are on the average valid representations of their measured counterparts. However, even when they occur, systematic errors in self-reported height, weight and BMI are negatively associated with the corresponding measured dimension and the prevalence of overweight based on BMI from self-reported measures is expected to be systematically underestimated relative to measured values [65]. As a result, even if these errors influence the results, this will be towards the null value, i.e. against our hypotheses.

Moreover, in this study we have used the variable of self-reported school performance and not variables based on objective data, such as official school grades or national examinations, which are expected to be more accurate measures of pupils' school performance. However, our objective in the current study was not to distinguish between academically good and worse students or investigate possible effects on adolescents' academic achievements, but to use a measure, which could reflect adolescents' own perceptions about their current position in the field where they are mainly active. This was the reason why we chose to use a subjective measure reported by the adolescent rather than objective data. We would like to note though that perceived academic achievement has been often used also in studies about bullying in schools [17].

Finally, we have used a subjective socioeconomic variable, namely adolescents' self-reports on the financial difficulties of their families. It has been suggested that directly questioning adolescents about their family's income can be unreliable [54]. In the literature financial difficulties of the family have been often used as a socioeconomic indicator in studies investigating socioeconomic health inequalities in populations of children and adults $[34,64]$. These studies have shown that more subjective indicators (such as financial difficulties, financial strain etc.) may be equally or even more important compared to more objective indicators of socio-economic status [64].

\section{Conclusions}

Bullying in school is a substantial problem for Greek youth. This study has shown that perpetration was independently associated with some dimensions of adolescents' socioeconomic status, while victimization showed no socioeconomic associations. Our findings indicate that lower socioeconomic status as expressed by typical and other measures is related to an increased risk of being a perpetrator. The current findings may add to our understanding of possible risk factors for bullying behaviours in adolescence. The identification of potential risk factors plays a decisive role in the design of effective anti-bullying programmes. Several countries have adopted anti-bullying measures in schools and some of them have been found to be effective at least in the short-term [66]. More has to be done, however, to maintain the results over longer periods. Greece has only recently started discussing the implementation of a national policy against bullying. International experience combined with relevant research findings could contribute significantly to the organisation of effective anti-bullying programmes in the school setting, the benefits of which are expected to appear not only in adolescence but also in later life [67].

\section{Additional material}

Additional file 1: Basic description of the sample in the two phases of the study, of victims and of perpetrators of bullying behaviours.

\section{Acknowledgements}

The authors would like to acknowledge the support of the Ministry of National Education which partly funded the study under the Pythagoras II 
research program (European Community Support Framework 2000-2006). Pythagoras II project was co-funded by the European Social Fund (75\%) and National Resources (25\%).

\section{Author details}

${ }^{1}$ Department of Psychiatry, University of Ioannina, School of Medicine, Ioannina, Greece. ${ }^{2}$ Academic Unit of Psychiatry, School of Social and Community Medicine, University of Bristol, Bristol, UK. ${ }^{3}$ Department of Psychology, Panteion University of Social and Political Sciences, Athens, Greece. ${ }^{4}$ Department of Psychiatry, University of Ioannina, School of Medicine, loannina 45110, Greece.

\section{Authors' contributions}

KM helped in data collection, contributed to the statistical analyses and drafted the manuscript. PS was responsible for the conception and design of the study, helped in data collection, contributed to the statistical analysis and helped in the writing of the paper and interpretation of the results. TG helped in data collection, in the writing of the paper and interpretation of the results. SB helped in data collection, in the statistical analysis and interpretation of the results. RA made critical comments and helped in the interpretation of the results. SS helped in data collection and made critical comments that helped in the interpretation of the results. VM helped in obtaining funding for the study, in the writing of the paper and interpretation of the results. All authors read and approved the final manuscript.

\section{Competing interests}

The authors declare that they have no competing interests.

Received: 21 August 2011 Accepted: 12 February 2012

Published: 12 February 2012

\section{References}

1. Boulton MJ, Underwood K: Bully/victim problems among middle school children. Br J Educ Psychol 1992, 62:73-87.

2. Olweus D: Bullying at School: What We Know and What We Can Do Oxford: Blackwell Publishers; 1993.

3. Delfabbro P, Winefield T, Trainor S, Dollard M, Anderson S, Metzer J, Hammarstrom A: Peer and teacher bullying/victimization of South Australian secondary school students: prevalence and psychosocial profiles. Br J Educ Psychol 2006, 76(1):71-90.

4. Abada $T$, Feng $H$, Bali R: The effects of harassment and victimization on self-rated health and mental health among Canadian adolescents. Soc Sci Med 2008, 67:557-567.

5. Bond L, Carlin JB Thomas L, Rubin K, Patton G: Does bullying cause emotional problems? A prospective study of young teenagers. BMJ 2001, 323(7311):480-484

6. Glew GM, Fan MY, Katon W, Rivara FP, Kernic MA: Bullying, psychosocial adjustment, and academic performance in elementary school. Arch Pediatr Adolesc Med 2005, 159(11):1026-1031.

7. Perren S, Dooley J, Shaw T, Cross D: Bullying in school and cyberspace: Associations with depressive symptoms in Swiss and Australian adolescents. Child Adolesc Psychiatry Ment Health 2010, 4:28.

8. Lien L, Green K, Welander-Vath A, Bjertness E: Mental and somatic complaints associated with school bullying 10th and 12th grade students from cross sectional studies in Oslo, Norway. Clinical Practise and Epidemiology in Mental Health 2009, 5:6

9. Williams K, Champers M, Logan S, Robinson D: Assotiation of common health symptoms with bullying in primary school children. BMJ 1996, 313:17-19.

10. Wolke D, Karstadt L: Physical and relational bullying in young children: distinguishing features. J Child Psychology Psychiatry 2000, 41(8):989-1002.

11. Herba K, Ferdinand R, Stijnen T, Veenstra R, Oldehinkel A, Ormel J, Verhulst F: Victimization and suicide ideation in the TRAILS study: specific vulnerabilities of victims. Journal of child and Psychology 2008, 49(8):867-876

12. Skapinakis P, Bellos S, Gkatsa T, Magklara K, Lewis G, Araya R, Stylianidis S, Mavreas $\mathrm{V}$ : The association between bullying and early stages of suicidal ideation in late adolescents in Greece. BMC Psychiatry 2011, 11:22.

13. Klomek AB, Sourander A, Niemelä S, Kumpulainen K, Piha J, Tamminen T, Almqvist F, Gould MS: Childhood bullying behaviors as a risk for suicide attempts and completed suicides: a population-based birth cohort study. J Am Acad Child Adolesc Psychiatr 2009, 48(3):254-261.

14. Kim YS, Leventhal BL, Koh YJ, Hubbard A, Boyce WT: School bullying and youth violence: causes or consequences of psychopathology? Arch Gen Psychiatry 2006, 63(9):1035-1041.

15. Sourander A, Jensen P, Ronning JA, Elonheimo H, Niemela S, Helenius $H$, Kumpulainen K, Piha J, Tamminen T, Moilanen I, Almqvist F: Childhood bullies and victims and their risk of criminality in late adolescence. Arch Pediatr Adolesc Med 2007, 161:546-552.

16. Wolke D, Woods S, Stanford K, Schulz H: Bullying and victimization of primary school children in England and Germany: prevalence and school factors. Br J Psychol 2001, 92(4):673-696.

17. Nansel TR, Overpeck M, Pilla RS, Ruan WJ, Simons-Morton B, Scheidt P: Bullying behaviors among US youth: prevalence and association with psychosocial adjustment. JAMA 2001, 285(16):2094-2100.

18. Baldry AC, Farrington DP: Brief report: types of bullying among Italian school children. J Adolesc 1999, 22(3):423-426

19. Kim YS, Koh YJ, Leventhal BL: Prevalence of school bullying in Korean middle school students. Arch Pediatr Adolesc Med 2004, 158:737-741.

20. Dake JA, Price JH, Telljohann SK: The nature and extent of bullying at school. J Sch Health 2003, 73(5):173-180.

21. Due P, Holstein BE, Lynch J, Diderichsen F, Gabhain SN, Scheidt P, Currie C, Health Behaviour in School-Aged Children Bullying Working Group: Bullying and symptoms among school-aged children: international comparative cross sectional study in 28 countries. Eur J Public Health 2005, 15(2):128-132.

22. Due $\mathrm{P}$, Holstein BE: Bullying victimization among 13-15 year old school children: results from two comparative studies in 66 countries and regions. Int J Adolesc Med Health 2008, 20(2):209-222.

23. Craig W, Harel-Fisch Y, Fogel-Grinvald H, Dostaler S, Hetland J, SimonsMorton B, Molcho M, de Mato MG, Overpeck M, Due P, Pickett W, HBSC Violence \& Injuries Prevention Focus Group, HBSC Bullying Writing Group: A cross-national profile of bullying and victimization among adolescents in 40 countries. Int J Public Health 2009, 54(2):216-224.

24. Whitney I, Smith PK: A survey of the nature and extent of bullying in junior/middle and secondary schools. Educ Res 1993, 35:3-25.

25. Kaltiala-Heino R, Rimpela M, Marttunen M, Rantanen P, Rimpela A: Bullying, depression and suicidal ideation in finnish adolescents: school survey. BMJ 1999, 319(7206):348-351.

26. Analitis F, Klein-Velderman M, Ravens-Sieberer U, Detmar S, Erhart M, Herdman M, Berra S, Alonso J, Rajmil L, European Kidscreen Group: Being bullied: associated factors in children and adolescents 8-18 years old in 11 European countries. Pediatrics 2009, 123:569-577.

27. Glew G, Rivara F, Feudtner C: Bullying: children hurting children. Pediatr Rev 2000, 21:183-190

28. Smith PK, Cowie H, Olafsson R, Liefooghe APD, et al: Definitions of bullying: a comparison of terms used, and age and sex differences, in a 14-country international comparison. Child Dev 2002, 73:1119-1133.

29. Due P, Merlo J, Harel-Fisch Y, Damsgaard MT, Holstein BE, Hetland J, Currie C, Gabhainn SN, de Matos MG, Lynch J: Socioeconomic inequality in exposure to bullying during adolescence: a comparative, crosssectional, multilevel study in 35 countries. Am J Public Health 2009, 99(5):907-914.

30. Perren S, Stadelmann S, von Klitzing K: Child and family characteristics as risk factors for peer victimization in kindergarten. Schweizerische Zeitschrift für Bildungswissenschaften 2009, 31(1):13-32.

31. Kumpulainen K, Räsänen $E$, Henttonen I: Children involved in bullying: psychological disturbance and the persistence of the involvement. Child Abuse Negl 1999, 23(12):1253-1262.

32. Due P, Krølner R, Rasmussen M, Andersen A, Trab Damsgaard M, Graham H, Holstein BE: Pathways and mechanisms in adolescence contribute to adult health inequalities. Scand J Public Health 2011, 39(6 suppl):62-78.

33. Elgar FJ, Craig W, Boyce W, Morgan A, Vella-Zarb R: Income inequality and school bullying: multilevel study of adolescents in 37 countries. J Adolesc Health 2009, 45(4):351-359.

34. Skapinakis P, Weich S, Lewis G, Singleton N, Araya R: Socio-economic position and common mental disorders. Longitudinal study in the general population in the UK. Br J Psychiatry 2006, 189:109-117.

35. Skapinakis P, Magklara K, Mpellos S, Gkatsa T, Mihalis G, Mavreas V: The association between socio-economic status and mental disorders in late 
adolescence: cross-sectional survey in the Northwestern part of Greece. Archives of Hellenic Medicine 2007, 24(1):19-29.

36. Magklara K, Skapinakis P, Niakas D, Bellos S, Zissi A, Stylianidis S, Mavreas V Socioeconomic inequalities in general and psychological health among adolescents: a cross-sectional study in senior high schools in Greece. Int J Equity Health 2010, 9:3.

37. Sawyer MG, Arney FM, Baghurst PA, Clark JJ, Graetz BW, Kosky RJ, Nurcombe B, Patton GC, Prior MR, Raphael B, Rey J, Whaites LC, Zubrick SR: Mental Health of Young People in Australia. Child and Adolescent Component of the National Survey of Mental Health and Well-Being Canberra: Commonwealth Department of Health and Aged Care; 2000.

38. Janssen I, Craig WM, Boyce WF, Pickett W: Associations between overweight and obesity with bullying behaviors in school-aged children. Pediatrics 2004, 113(5):1187-1194.

39. Bell LM, Byrne S, Thompson A, Ratnam N, Blair E, Bulsara M, Jones TW, Davis EA: Increasing body mass index z-score is continuously associated with complications of overweight in children, even in the healthy weight range. J Clin Endocrinol Metab 2007, 92(2):517-522.

40. Brixval CS, Rayce SL, Rasmussen M, Holstein BE, Due P: Overweight, body image and bullying-an epidemiological study of 11-15-years olds. Eur Public Health 2011, doi:10.1093/eurpub/ckr010.

41. Dunn G, Pickles A, Tansella M, Vazquez-Barquero JL: Two-phase epidemiological surveys in psychiatric research. Br J Psychiatry 1999, 174:95-100.

42. Lewis G, Pelosi AJ, Araya R, Dunn G: Measuring psychiatric disorder in the community: a standardised assessment for use by lay interviewers. Psychol Med 1992, 22:465-486.

43. Singleton N, Bumpstead R, O'Brien M, Lee A, Meltzer H: Psychiatric morbidity among adults living in private households 2000. Int Rev Psychiatry 2003, 15:65-73.

44. Lewis G, Pelosi AJ, Glover E, Wilkinson G, Stansfeld SA, Williams P, Shepherd M: The development of a computerized assessment for minor psychiatric disorder. Psychol Med 1988, 18:737-745.

45. Patton GC, Coffey C, Posterino M, Carlin JB, Wolfe R, Bowes G: A computerised screening instrument for adolescent depression: population based validation and application to a two-phase case-control study. Soc Psychiatry Psychiatr Epidemiol 1999, 34:166-172.

46. Skapinakis $P$, Anagnostopoulos F, Bellos S, Magklara K, Lewis G, Mavreas V: An empirical investigation of the structure of anxiety and depressive symptoms in late adolescence: cross-sectional study using the Greek version of the revised Clinical Interview Schedule. Psychiatry Res 2010, doi:10.1016/j.psychres.2010.08.023.

47. Singleton N, Lewis G: Better or Worse: A Longitudinal Study of the Mental Health of Adults Living in Private Households 2000 London: TSO (The Stationery Office); 2003.

48. Patel V, Araya R, Chowdhary N, King M, Kirkwood B, Nayak S, Simon G, Weiss HA: Detecting common mental disorders in primary care in India: a comparison of five screening questionnaires. Psychol Med 2008, 38(2):221-228.

49. Olweus D: The Revised Olweus Bully/Nictim Questionnaire Bergen, Norway: University of Bergen; 1996.

50. WHO: Health and Health Behaviour Among Young People: Health Behaviour in School-Aged Children: A WHO Cross-National Study (HBSC): International Report Copenhagen: Health Promotion and Investment for Health, World Health Organization Regional Office for Europe; 2000

51. van der Lucht F, Groothoff JW: Social inequalities and health among children aged 10-11 in the Netherlands: causes and consequences. Soc Sci Med 1995, 40:1305-1311.

52. Ray R, Gornick JC, Schmitt J: Parental Leave Policies in 21 Countries: Assessing Generosity and Gender Equality. 2008 edition. Washington DC: Centre for Economic and Policy Research; 2008.

53. Lahelma E, Martikainen P, Laaksonen M, Aittomaki A: Pathways between socioeconomic determinants of health. $J$ Epidemiol Community Health 2004, 58(4):327-332.

54. Currie CE, Elton RA, Todd J, Platt S: Indicators of socioeconomic status for adolescents: the WHO health behaviour in school-aged children survey. Health Educ Res 1997, 12:385-397.

55. Koivusilta LK, Rimpelä AH, Kautiainen SM: Health inequality in adolescence. Does stratification occur by familial social background, family affluence or personal social position? BMC Publ Health 2006, 6:110.
56. Rabe-Hesketh S, Skrondal A: Multilevel and Longitudinal Modelling Using Stata College Station, TX: Stata Press; 2008

57. Monks CP, Smith PK: Definitions of bullying: age differences in understanding of the term, and the role of experience. Br J Dev Psychol 2006, 24(4):801-821.

58. Smith PK, Cowie H, Olafsson RF, Liefooghe AP, Almeida A, Araki H, del Barrio C, Costabile A, Dekleva B, Houndoumadi A, Kim K, Olafsson RP, Ortega R, Pain J, Pateraki L, Schafer M, Singer M, Smorti A, Toda Y, Tomasson $\mathrm{H}$, Wenxin Z: Definitions of bullying: a comparison of terms used, and age and gender differences, in a 14-country international comparison. Child Dev 2002, 73(4):1119-1133.

59. Kumpulainen K, Räsänen E, Puura K: Psychiatric disorders and the use of mental health services among children involved in bullying. Aggress Behav 2001, 27(2):102-110.

60. Bacikova-Sleskova M, Madarasova Geckova A, van Dijk JP, Groothoff JW, Reijneveld SA: Parental support and adolescents' health in the context of parental employment status. J Adolesc 2011, 34(1):141-149.

61. Nordhagen R, Nielsen A, Stigum H, Köhler L: Parental reported bullying among Nordic children: a population-based study. Child Care Health Dev 2005, 31(6):693-701.

62. Sleskova M, Salonna F, Geckova AM, Nagyova I, Stewart RE, van Dijk JP, Groothoff JW: Does parental unemployment affect adolescents' health? J Adolesc Health 2006, 38(5):527-535.

63. Wang J, lannotti RJ, Nansel TR: School bullying among adolescents in the United States: physical, verbal, relational, and cyber. J Adolesc Health 2009, 45(4):368-375.

64. Piko BF, Fitzpatrick KM: Socioeconomic status, psychosocial health and health behaviours among hungarian adolescents. Eur J Public Health 2007, 17(4):353-360.

65. Himes JH, Hannan P, Wall M, Neumark-Sztainer D: Factors associated with errors in self-reports of stature, weight, and body mass index in Minnesota adolescents. Ann Epidemiol 2005, 15(4):272-278

66. Mytton J, DiGuiseppi C, Gough D, Taylor R, Logan S: School-based secondary prevention programmes for preventing violence. Cochrane Database Syst Rev 2006, 3:CD004606.

67. Sourander A, Jensen P, Rönning JA, Niemelä S, Helenius H, Sillanmäki L Kumpulainen K, Piha J, Tamminen T, Moilanen I, Almqvist F: What is the early adulthood outcome of boys who bully or are bullied in childhood? The Finnish "From a Boy to a Man" study. Pediatrics 2007, 120(2):397-404.

doi:10.1186/1753-2000-6-8

Cite this article as: Magklara et al:: Bullying behaviour in schools, socioeconomic position and psychiatric morbidity: a cross-sectional study in late adolescents in Greece. Child and Adolescent Psychiatry and Mental Health 2012 6:8.

\section{Submit your next manuscript to BioMed Central and take full advantage of:}

- Convenient online submission

- Thorough peer review

- No space constraints or color figure charges

- Immediate publication on acceptance

- Inclusion in PubMed, CAS, Scopus and Google Scholar

- Research which is freely available for redistribution

Submit your manuscript at www.biomedcentral.com/submit
C Biomed Central 